\title{
Economia de Minas e economia da mineração em Celso Furtado
}

Mauricio C. Coutinho

Professor do Instituto de Economia da Unicamp

\begin{abstract}
Palauras-chave
Celso Furtado, economia da mineração, Minas Gerais.
\end{abstract}

Classificação JEL B31, N01.

Key words

Celso Furtado, mining economy, Minas Gerais.

JEL Classification B31, N01.

\section{Resumo}

$\mathrm{O}$ artigo tem por objetivo contribuir para o entendimento do modelo de abstração da história econômica brasileira de Celso Furtado, por meio da análise do ciclo da mineração. O ciclo da mineração ocorrido em Minas Gerais no século XVIII é posto em contraste com os dois outros ciclos induzidos por demanda externa - o ciclo açucareiro e o do café-, assim como confrontado com o modelo geral de economia mineradora, presente nos estudos sobre a América hispânica. Entendemos que por meio destes contrastes podem-se entender as notórias lacunas a respeito do desenvolvimento do escravismo em Minas Gerais no século XIX, presentes em Formação Econômica do Brasil e, em especial, divisar os principais elementos da teoria econômica subjacente aos modelos de abstração histórica de Furtado.

\begin{abstract}
The paper aims at a better understanding of the abstract modeling of the Brazilian Economic History, exposed by Celso Furtado in his celebrated essay The Economic Growth of Brazil. The mining cycle of 18 th century Minas Gerais is contrasted with the two other main export-led cycles of the Brazilian economy: the Northeastern sugar-cane cycle and the coffee crop cycle. It is also confronted with the general model for a mining economy, to be found in Furtado's studies about Hispanic America. In our view, these contrasts allow us a better understanding of the notorious flaws of Furtado's hypotheses on the development of the slave economy in 19th century Minas Gerais. Additionally, these contrasts may prove instrumental to the understanding of the economic theory underneath Furtado's models of historical abstraction.
\end{abstract}




\section{1_Introdução}

Pode-se dizer que o volume de pesquisas históricas sobre o escravismo no Brasil, dos últimos 20 anos, produziu nas hipóteses de Celso Furtado sobre a economia escravista um abalo comparável ao que havia sido provocado no modelo clássico de industrialização, anos antes, pelas abundantes evidências empíricas referentes à indústria brasileira no pré-1930 (ver a respeito Suzigan, 2001; Dean, 1971; Villela, 2000). Admite-se hoje que as bases empíricas dos modelos de economia escravista de Formação Econômica do Brasil são incompletas, inconsistentes mesmo.

A constatação aplica-se com vigor ainda maior à abordagem da economia da mineração do século XVIII e, particularmente, às especulações de Furtado a respeito do destino do escravismo em Minas Gerais nos momentos subseqüentes à decadência das minas. De fato, a opinião de que a economia mineira do século XIX entrou em marasmo é desmentida pelo vigor das atividades agrícolas e, mais ainda, pelas evidências de que o contingente de escravos não decresceu ao longo do século. Ao contrário, Minas Gerais manteve-se como pólo de atração de escravos até a abolição (ver a respeito Martins Filho e Martins, 1983; Martins, 1982; Paiva, 1996; Libby, 1988).
É razoável admitir que, dos três grandes ciclos primário-exportadores analisados em Formação Econômica do Brasil - cana-deaçúcar, mineração, café -, o da mineração recebe a menos satisfatória das abordagens da decadência. $O$ contraste na abordagem dos três ciclos é expressivo. Afinal, o término do ciclo do café coincidiu com a expansão da indústria, e as teses de Furtado sobre a transição da etapa primário-exportadora para o desenvolvimento baseado no mercado interno foram muito inovadoras. Do mesmo modo, o sofisticado retrato que Furtado traça da economia colonial açucareira foi baseado em um conhecimento razoável da cultura de cana-de-açúcar. ${ }^{1}$ Das minas, Furtado conhecia muito pouco; e menos ainda do que sucedeu à região mineira no século XIX. Suas conclusões, desse modo, estão pouco referidas ao quadro histórico real. Pode-se dizer que se sustentam, em grau bem maior do que no restante do livro, em racionalizações construídas com base em um modelo geral de história econômica brasileira.

O objetivo do presente trabalho é justamente trazer à tona os princípios de análise econômica subjacentes ao modelo geral de história econômica de Furtado, em suas aplicações imediatas à economia das minas. Cabe antecipar que o artigo não tem qualquer compromisso com a revisão his-
Sua tese de doutoramento (Furtado, 2000) foi sobre a economia colonial açucareira. 
tórica ou historiográfica. Procura, exclusivamente, efetuar uma digressão em história do pensamento econômico, alimentada pelo entendimento de que o modelo de economia da mineração proporciona um bom ângulo de abordagem à "teoria econômica" de Celso Furtado. Vale dizer que as interpretações do autor sobre a economia de Minas Gerais, em particular, e sobre a mineração, de modo geral, contribuem para o esclarecimento das bases teóricas de seu sistema de reconstrução racional da história - o núcleo da obra de Furtado. Por outro lado, e no sentido inverso, acreditamos que a "teoria econômica" de Furtado permite entendermos o porquê de suas conclusões, assim como as lacunas de suas hipóteses (e conclusões) a respeito da economia das minas e de Minas.

\section{A economia do ouro do século XVIII}

$\mathrm{Na}$ terceira parte de Formação Econômica do Brasil, em três breves capítulos, Celso Furtado trata da economia escravista mineira do século XVIII. A análise articula-se em torno do esquema do fluxo de renda da economia mineradora, do qual, a rigor, obtém-se melhor compreensão mediante o contraste com os fluxos de renda da economia açucareira do Nordeste, nos séculos XVI e XVII, e do café do Sudeste, nos séculos XIX e XX. Entre os três grandes ciclos da economia brasileira impulsionados pela demanda externa - açúcar, mineração, café -, o da mineração apresenta posição ímpar, no sentido de estar mais bem definido pelas diferenças em relação aos outros dois.

Como é bem sabido, na visão de Furtado, o ciclo do café representou um ponto de virada no desenvolvimento econômico brasileiro, por ter aberto as portas à utilização massiva de trabalho livre. Por sua vez, o ciclo açucareiro segue o modelo prototípico da plantation escravista. Já o ciclo minerador do século XVIII é atípico: baseia-se no trabalho escravo, porém, oferece muitas oportunidades para o trabalho livre; ao contrário do que ocorrera com a atividade açucareira, estimulou os nexos com setores econômicos fornecedores, fortaleceu a Coroa e as atividades urbanas, assim como diversificou a economia. Enfim, apesar de escravista, a economia do ouro contrasta fortemente com o modelo de plantation açucareira, o que recomenda uma recapitulação de suas (da plantation açucareira) principais características.

A economia do açúcar nordestino, de acordo com Furtado, caracterizou-se por:

1. dominância da grande propriedade agrícola, ou das grandes unidades de capital; 
2. presença desprezível de mão-deobra livre e/ou de população trabalhadora branca, com inteira dominância do trabalho escravo;

3. auto-suficiência da propriedade rural, que tanto produz o bem de exportação quanto os meios de subsistência da escravaria;

4. ausência de nexos econômicos significativos entre o setor exportador e o restante da economia, considerado "economia de subsistência";

5. baixo nível de monetização das atividades econômicas internas, seja porque as transações do engenho de açúcar com o restante da economia são insignificantes, seja porque, no interior da firma açucareira, sendo escrava a mão-de-obra, não há pagamento a fatores; ${ }^{2}$

6. os fluxos monetários concentram-se na esfera das relações internacionais (receita de exportação, pagamento de juros no exterior, importação de equipamentos e dos bens de consumo da classe proprietária).

$\mathrm{Na}$ verdade, Furtado admite alguma presença de transações monetárias entre o engenho açucareiro e os setores fornecedores, particularmente no que se refere ao fornecimento de lenha e gado. Considera, no entanto, que são transações residuais, responsáveis por menos de $5 \%$ da renda gerada na economia. Além disso, o esquema explicativo de Formação Econômica do Brasil deixa na obscuridade a economia urbana e o abastecimento das cidades. A vida econômica do Nordeste girava em torno da grande propriedade rural açucareira, que era praticamente auto-suficiente. Os transbordamentos do negócio do açúcar, como a criação de gado do sertão, representavam economias escassamente monetizadas e de baixa produtividade.

$\mathrm{Na}$ economia mineradora, ao contrário, cresce a importância da mão-de-obra livre. A despeito do papel central do trabalho escravo, o ciclo do ouro motivou o influxo de imigrantes portugueses de diversas condições sociais. De acordo com Furtado, a desconcentração dos negócios - o ouro podia ser explorado tanto por produtores abastados como por faiscadores descapitalizados -, bem como a diversificação inerente às economias urbanas, ensejou uma diferenciação social e de ocupações, além da intensificação dos fluxos monetários.

A firma mineradora não desfrutava de auto-suficiência. Totalmente concentrada na atividade extrativa, adquiria alimentos para os escravos, pagava transporte, demandava bens e serviços diversos. Se admitirmos que essas aquisições envolviam
2 A rigor, ocorre o pagamento de lucros. A renda concentra-se fortemente, o que favorece o consumo de produtos de luxo das classes proprietárias e o investimento na expansão da lavoura. 
3 No decênio $1750-60$

a exportação de ouro

manteve-se em torno de

2 milhões de libras.

$4 / 5$ correspondiam à região

mineira $(2 \times 4 / 5=1,6)$.

As importações equivalem às exportações. O coeficiente de importações é 0,5 ; logo a renda regional seria igual a $3,2(1,6 / 0,5)=3,2$. Furtado afirma que "a renda anual da economia não seria superior a 3,6 milhöes de libras ..." (Furtado, 1999, p. 78). dinheiro, teria ocorrido aumento geral do grau de monetização da economia, um resultado crucial, já que, no esquema explicativo de Furtado, a ativação do mecanismo multiplicador de renda depende da existência de transações monetárias. O núcleo minerador chegou até mesmo a articular atividades econômicas em outras regiões - é o caso das tropas de muares do extremo Sul, da compra de gado bovino do Sul e do Nordeste-, assim contribuindo para elevar o grau de monetização e de integração da economia em todo o território colonial.

A diversificação econômica e, particularmente, o pagamento de bens e serviços redefinem o fluxo de renda. Na economia açucareira, o grosso das transações monetárias envolvia o engenho e o exterior. Já na economia mineira do século XVIII, as aquisições e o pagamento de serviços diversos em dinheiro espalhavam a renda para além da firma mineradora. Em um compacto (e confuso) cálculo com base nos valores das exportações de ouro, Furtado estima que a renda da região mineira tenha atingido 3,6 milhões de libras na época de maior prosperidade. ${ }^{3}$ Reconhece que, em relação à economia açucareira, [...] as importaçôes representavam menor proporção do dispêndio total (Furtado, 1999, p. 79). Havia demanda (e produção) no mercado interno. De fato, o coeficiente de importações ad- mitido no cálculo da renda $(0,5)$ implica a geração de renda monetária fora do núcleo exportador.

Além disso, fatores como a menor concentração de renda, os elevados custos de transporte inerentes a uma atividade econômica afastada do litoral contribuíram para modificar a composição da procura em favor dos bens de consumo corrente. Em comparação com o Nordeste açucareiro, o ambiente econômico tornou-se propício ao desenvolvimento de atividades de mercado interno. $\mathrm{O}$ fato é que, admitido o dinamismo das atividades internas, a coerência do modelo passa a depender de dois elementos. Em primeiro lugar, das explicações para o suposto declínio da economia aos níveis de subsistência, após a exaustão das minas. Adicionalmente, de hipóteses sobre as razões do fracasso no desenvolvimento de manufaturas, uma vez que a constituição de uma base manufatureira representaria o desdobramento natural das transações monetárias e do acionamento do mecanismo multiplicador.

Cabe ressaltar que, em relação ao não-desenvolvimento de uma base manufatureira em Minas Gerais durante o ciclo do ouro, Furtado não se prende a explicações baseadas em vantagens comparativas da Europa ou normas impeditivas de constituição de indústria no Brasil. As razões 
aventadas chegam a ser prosaicas: teria faltado capacitação técnica, ou experiência manufatureira, aos imigrantes portugueses. Houvesse indivíduos com a devida qualificação, nem mesmo os tratados restritivos entre Portugal e Inglaterra teriam impedido a erupção de atividades manufatureiras.

Furtado vale-se do exemplo norteamericano para reafirmar que muitas das restrições estabelecidas por tratados internacionais ou pelo domínio colonial só não são contornadas na prática quando inexistem as bases econômicas para tanto. Editos governamentais não conseguem suprimir tendências econômicas vigorosas. Formação Econômica do Brasil utiliza o exemplo do desenvolvimento da Austrália do século XIX para mostrar como o declínio de uma atividade mineradora pode levar à diversificação econômica. Em Minas, ao contrário do que viria a ocorrer na Austrália (100 anos depois...), o declínio da mineração levou a uma regressão da atividade econômica.

Foi exatamente a falta de desdobramento da economia mineira [... num sistema mais complexo [... (Furtado, 1999, p. 84) um sistema manufatureiro -, que levou à regressão econômica. No entender de Furtado, não se haviam criado nas regiões mineiras [...] formas permanentes de atividade econômica - à exceção de alguma agricultura de subsistência [...] (Furtado, 1999, p. 84).
Note-se que, por agricultura de subsistência, não necessariamente se entende agricultura não-excedentária. Os alimentos e as matérias-primas utilizados na economia urbana e nas minas provinham dos "setores de subsistência", assim como a criação de gado no sertão para o abastecimento do litoral nordestino representou "economia de subsistência". Posteriormente, voltaremos a esse ponto.

Por outro lado, e como foi visto, a economia das minas articulou um sistema de trocas monetárias entre o núcleo minerador, as cidades e os produtores de bens agrícolas. Pois bem, tal sistema desaparece quando o ouro escasseia. Ocorre um processo de atrofiamento da economia monetária (Furtado, 1999, p. 85) e, em paralelo, um rebaixamento do nível de produtividade na economia como um todo.

É importante observar que, no sistema de Furtado, as elevações de produtividade em uma economia primário-exportadora decorrem de dois fatores. Em primeiro lugar, os produtos líderes de exportação têm preço elevado, o que representa uma elevação da renda monetária (ou do poder de compra) da comunidade. Em segundo lugar, a integração da economia a uma corrente de comércio internacional possibilita a ativação de fatores - terra, mão-de-obra que de outro modo permaneceriam ocio- 
sos. Pelos dois lados - elevação dos preços e aproveitamento de fatores ociosos -, cresce a produtividade dos fatores. Simetricamente, o colapso das exportações provoca diminuição da produtividade, seja pela ausência de um produto de elevado valor na economia, seja pelo refluxo dos fatores para uma ou outra forma de ociosidade. Voltaremos adiante à questão da produtividade.

Em suma, nunca é demais ressaltar a importância da demanda externa nos modelos de crescimento econômico de Furtado. No limite, foi a ausência de demanda externa que atrofiou a economia mineira ao término do ciclo do ouro. Até que o surgimento do trabalho assalariado e o de uma base industrial tivessem possibilitado o desenvolvimento baseado no mercado interno, os surtos de crescimento dependeram sempre da conexão com uma fonte dinâmica de demanda externa. Rompida a conexão, o declínio torna-se inevitável.

Os próprios processos de industrialização bem-sucedidos, em países de origem colonial, não deixam de estar associados a um mercado internacional dinâmico. No caso do Brasil, a percepção da importância do surto exportador do café para o nascimento da indústria permanece semisubmersa porque, no conhecido relato da industrialização de Formação Econômica do Brasil, o objetivo principal é mostrar o pa- pel especial desempenhado pela crise dos anos 30 na ruptura do padrão primário-exportador. Para conferir destaque à crise econômica mundial e à decorrente compressão da capacidade de importar, Furtado deixa na penumbra a indústria preexistente. Não obstante, e sempre de acordo com Furtado, foi o café que propiciou o surgimento de uma economia urbana diversificada, a formação de um mercado de trabalho assalariado e até mesmo de uma base industrial, cuja capacidade ociosa foi o suporte para a recuperação econômica dos anos 30 .

Os comentários ao desenvolvimento norte-americano reforçam o papel decisivo da inserção internacional. Como se sabe, Furtado gostava de recorrer ao contraste entre as colonizações ibérica e inglesa, bem como de ressaltar os fatores distintivos presentes na ocupação do território norteamericano: a capacitação da mão-de-obra e a absorção do excedente populacional na Inglaterra, o papel positivo da pequena propriedade no novo território, a visão esclarecida das lideranças da república nascente... $\mathrm{O}$ autor não deixou de assinalar, no entanto, a relevância do comércio triangular com as Antilhas, na época colonial, e, após a independência dos Estados Unidos, o papel crucial da plantation algodoeira sulista. Vale dizer, insistiu no papel decisivo 
da demanda externa no progresso norteamericano. O capítulo XVIII de Formação Econômica do Brasil, "Confronto com o Desenvolvimento dos EUA", destaca a importância do cultivo e das exportações de algodão, que lograram articular a nascente república ao núcleo dinâmico da revolução industrial (a indústria têxtil) nos cinqüenta anos subseqüentes à independência. ${ }^{4}$

\section{3 - O modelo de economia da mineração}

Em sua obra, Furtado explicita um modelo geral de economia da mineração, inteiramente distinto do modelo de economia do ouro do Brasil do século XVIII, aplicável, com variações, a diversos países da América hispânica. Em Formação Econômi ca da América Latina, o modelo de economia da mineração é um dos que integram a "tipologia das economias exportadoras de matérias-primas" que resultam da expansão do comércio internacional na segunda metade do século XIX.

De acordo com a tipologia, haveria três grupos de países exportadores de produtos primários:

a) paises exportadores de produtos agricolas de clima temperado, b) países exportadores de produtos agricolas tropicais, e c) paises exportadores de produtos minerais (Furtado, 1969, p. 41-42).
O último grupo compreende o México, o Chile, o Peru e a Bolívia, produtores de minerais não-ferrosos cuja demanda cresceu a partir da segunda metade do século XIX. $^{5}$

A característica básica dessas economias minerais é a presença de grande progresso tecnológico nas minas, que são de propriedade estrangeira (em geral, norte-americana). A desnacionalização, bem como a utilização de técnicas modernas e pouco empregadoras de mão-de-obra, converte as atividades mineradoras em espécies de enclaves estrangeiros de elevada capitalização, o que [...] significaria desvincular da economia interna a parte principal do fluxo de renda a que dá origem essa atividade (Furtado, 1969, p. 64). Em resumo, a mineração moderna implica transferência de renda para o exterior, fluxos reduzidos de salários no interior da economia, pouca ou nenhuma articulação com os demais setores de atividade econômica, reduzida contribuição à expansão de mercados internos.

Ao individualizar um modelo de economia da mineração na América Latina já independente, Furtado persegue dois objetivos. Por um lado, estabelecer o contraste com as economias dos dois outros grupos de países - exportadores de produtos agrícolas de clima temperado e tropical -, nos quais as exportações exerceram impacto
4 O algodão constitui o principal fator dinâmico do desenvolvimento da economia norte-americana na primeira metade do século XIX (Furtado, 1969, p. 104). Devo a Maria Alice Rosa Ribeiro as observações sobre o papel decisivo da agricultura algodoeira (e da demanda externa) na constituição de uma base manufatureira e industrial nos Estados Unidos, na interpretação de Furtado.

5 O grupo compreende ainda a Venezuela, que se tornou exportadora de petróleo no século XX. 
6 Nos paises exportadores de produtos agrícolas, o dualismo era menos visivel, mas nem por isso menos real, pelo menos na fase inicial (Furtado, 1969, p. 62). bem maior sobre o mercado interno. Por outro, e em decorrência, salientar a existência de dualismo nas economias latino-americanas, o que é bem mais visível nas economias mineradoras do que nas exportadoras de produtos agrícolas. ${ }^{6}$

O modelo de economia da mineração do século XIX contrasta também com o modelo de produção de metais preciosos da época colonial, em especial o dos países de colonização hispânica. Neste último caso, as regiōes produtoras dos metais ... comportaram-se como autênticos pólos de crescimento (Furtado, 1969, p. 35). Furtado refere-se à constituição de áreas produtoras de alimentos, animais de tiro e produtos artesanais para o abastecimento dos núcleos mineradores de prata, sob o regime de grande propriedade e de arregimentação de trabalho indígena por meio das encomiendas. Em poucas palavras, a mineração colonial de metais preciosos dinamizou a economia interna - algo que também se aplica ao ciclo do ouro em Minas Gerais.

A exaustão das minas de prata pôs em xeque a instituição da encomienda, ao enfraquecer a demanda por produtos agrícolas, sem eliminar contudo o regime de grande propriedade; apenas refizeram-se os vínculos de subordinação entre os fazendeiros e os trabalhadores rurais. As fazendas sobreviveram como unidades isoladas, destina- das à produção de subsistência, mas ainda assim dotadas de grande capacidade de arregimentação política e de submissão da população de origem indígena.

É flagrante o contraste entre as dinâmicas das economias coloniais de origem hispânica (mineração de prata) e portuguesa (açúcar e mineração de ouro). No caso da plantation açucareira, a crise de mercado, decorrente da concorrência internacional e da desregulamentação da oferta, teria produzido unidades agrícolas estagnadas, mas capazes de reter mão-de-obra escrava e sustentar o padrão de produção e de relações sociais típicos dos engenhos. Furtado fala em "letargia secular". Os segmentos conexos, por outro lado, como a pecuária do sertão nordestino, até mesmo se expandiram, a despeito do isolamento e do enfraquecimento dos vínculos com o núcleo litorâneo. Nos momentos em que a demanda externa se rearticulava, os engenhos conseguiam responder sem muitas alterações nas relações sociais e nos padrões produtivos, em comparação aos prevalecentes nos séculos XVI e XVII.

Já a exaustão das minas de ouro, como vimos, teria provocado a dispersão da população - proprietários, trabalhadores livres e escravos - na economia de subsistência, ou seja, o retrocesso irrecuperável a atividades de baixa produtividade. Furtado 
não esclarece o que são essas atividades, porém, descarta a possibilidade de que os capitais aplicados na mineração tenham se transferido em massa para outras regiões em busca de melhores oportunidades. Teria prevalecido uma espécie de racionalidade de jogos de azar: os mineradores relutavam em desmobilizar o capital e vender os escravos, graças à expectativa de um novo golpe de sorte na descoberta de lavras. Com isso, o capital desapareceu.

De todo modo, um novo surto de crescimento baseado na demanda externa viria a ocorrer apenas com a expansão da demanda externa pelo café, duas ou três gerações após o declínio da mineração. Teria havido um hiato no crescimento econômico e, como se sabe, o texto de Formação Econômica do Brasil pouco discute o que ocorreu na região das minas com a desarticulação do mercado externo, tanto imediatamente (século XVIII) quanto após o surgimento do núcleo dinâmico do café. A bem da verdade, os modelos de explicação baseados em ciclos comandados pela demanda externa de produtos primários pouca atenção conferem ao que ocorre nas regiões onde se deu o surto de crescimento, uma vez cessado o dinamismo. Feita a ressalva, deve-se admitir que a hipótese da "letargia secular" do açúcar tem peso e consistência - chega a ser um clássico de
Furtado. Em contraste, as lacunas de sua visão da economia mineira após o esgotamento das minas são gritantes.

O que interessa ao presente trabalho, no entanto, não é a acuidade histórica das conclusões de Formação Econômica do Brasil a respeito da economia de Minas Gerais após a decadência das minas. $\mathrm{O}$ relevante para o entendimento do método teórico-histórico de Furtado é o exame das características básicas do modelo de mineração colonial português, e o estabelecimento de contrastes e/ou semelhanças com seus congêneres hispânicos, com o modelo de plantation açucareira e com o modelo de economia mineral do século XIX. Como vimos, a economia do ouro envolveu:

a. diversificação social (coexistência de trabalho livre e escravo) e desconcentração da renda, em relação ao modelo clássico de plantation;

b. ativação de núcleos fornecedores (a empresa mineradora não é autosuficiente);

c. monetização da economia;

d. formação de uma economia urbana e, portanto, a admissão de que existia uma razoável diferenciação de ocupações.

Em suma, apesar de apoiada na mão-deobra escrava, a economia do ouro em tu- 
do diferiu da economia de plantation. Diferiu também da atividade mineradora moderna porque esta, embora apoiada no trabalho livre, baseava-se em tecnologias poupadoras de mão-de-obra e, portanto, exacerbadoras do dualismo. A economia mineral do século XIX não se integrou aos tecidos nacionais.

Ficam aqui diversas questões. Por que razão as atividades despertadas pela economia do ouro, a despeito da diversificação, foram incapazes de manter-se de pé após a exaustão das minas? O que explica o retorno às atividades de subsistência, ou a retração absoluta das trocas monetárias? $\mathrm{Na}$ verdade, as respostas dadas por Furtado são apenas aquelas que não colidem com seu modelo histórico de desenvolvimento econômico, cujos traços básicos são comentados a seguir.

\section{4_ Os traços básicos do modelo de Furtado}

Para entendermos a rationale do modelo de economia colonial de Minas Gerais, bem como a do retorno da região à situação de subsistência, supostamente ocorrido no século XIX, é conveniente explicitarmos certas características do método de reconstrução racional da história, extensamente praticado em Formação Econô- mica do Brasil e em outras obras. Acreditamos que há quatro tópicos que, sem esgotarem o universo dos elementos de análise econômica aplicada à história, típicos da visão de Furtado, permitem o entendimento das restrições de seus modelos de racionalização histórica, em particular o do ciclo do ouro (auge e período subseqüente). Os tópicos são:

i. transações monetárias e pagamento de fatores;

ii. significados de produtividade;

iii. preços relativos;

iv. economia de subsistência.

\section{1_Transações monetárias e pagamento de fatores}

$\mathrm{Na}$ visão de Furtado, ocorre uma verdadeira revolução na economia quando as transações efetuam-se com moeda e, especialmente, quando há contratação/pagamento de fatores na forma monetária. A disseminação do pagamento de fatores, que teve seu ponto culminante no assalariamento, foi um fenômeno iniciado no auge do período de domínio do capital mercantil na Europa, quando os comerciantes passam a contratar a produção junto aos produtores artesanais (ver Furtado, 1954). A contratação e a subordinação dos produtores passaram a exigir a pronta liquidação dos negócios para o 
ressarcimento dos trabalhadores e dos fornecedores de matérias-primas. A urgência é acrescida ainda pela expansão das cadeias de crédito, uma vez que os credores impõem retornos em prazos determinados. De acordo com Furtado, esse episódio de contratação de fatores e expansão do crédito tem como conseqüência a transição do "lucro comercial" para o "lucro industrial". Enquanto o lucro comercial admite o entesouramento dos ganhos, o lucro industrial exige pronta liquidação e pagamentos de credores, fornecedores e subordinados, sob risco de rompimento das cadeias de produção e comércio e/ou de perda de mercado. $\mathrm{Na}$ visão de Furtado, é a urgência em liquidar as operações o que aguça a concorrência e força a reorganização da produção e a inovação, visando redução de custos, penetração em mercados, etc. Em suma, a contratação da produção, o pagamento de fatores e a decorrente necessidade de liquidação dão início a uma concorrência irrefreável e à remodelação da produção manufatureira.

Por outro lado, são os pagamentos em forma monetária que ativam o mecanismo multiplicador. Atua aqui o conhecido multiplicador keynesiano de gastos, o qual, para Furtado, só se aplica a economias plenamente monetizadas e, com especial ênfase, submetidas ao regime de assalariamento. Desse modo, entende-se o caráter truncado do fluxo circular de renda na escravidão moderna ou colonial. A plantation açucareira nordestina apresenta o fluxo de renda mais restrito, porque nela, segundo Furtado, praticamente não há pagamentos em dinheiro no interior do território. Os escravos produzem os próprios alimentos, as transações são residuais (lenha e gado), e o contingente de funcionários assalariados e/ou de artesãos contratados é exíguo. Os pagamentos expressivos - compra de escravos, equipamentos, pagamento a credores internacionais, aquisição de bens de luxo representam importações e/ou pagamento de fatores no exterior, e portanto "vazamentos" do fluxo circular de renda.

No outro extremo, o ciclo do café representou verdadeira revolução econômica, porque nele ocorreu a combinação virtuosa de fatores como a abundância de terras, a posição quase monopolista do Brasil no mercado internacional e, com especial ênfase, a transição ao regime de trabalho livre em virtude do término da escravidão. Para Furtado, o trabalho em regime de colonato do café do oeste paulista equivale ao assalariamento, mesmo que parte do pagamento da mão-de-obra dê-se de forma não imediatamente monetária (cessão de terras para o plantio de cereais, meação...), já que, 
; . . . . . . . . . Neste caso, ganho nos termos de troca.

8 A despeito de ter sido um leitor atento de Antonil. ao final, os produtos dos colonos serão vendidos. Em uma ou outra modalidade de remuneração, haverá circulação de dinheiro, contratação de serviços urbanos, compra de produtos. Enfim, a economia cafeeira é plenamente monetária, e boa parte dos pagamentos é feita no interior do País, o que leva ao pleno funcionamento do multiplicador.

A economia mineira do ouro no século XVIII ocupa posição intermediária. O escravismo convive com o trabalho livre, a subsistência dos escravos é compra$\mathrm{da}$, as ocupações urbanas se diversificam, o pagamento de transportes é relevante. Em suma, pagamentos são feitos, e o dinheiro circula no interior do território, a despeito da escravidão. A tal ponto a economia se diversifica que Furtado é levado a especular sobre as razões de não se haver constituído uma economia manufatureira mais estável, com condições de sobreviver ao declínio da mineração. Vimos anteriormente que a resposta é bastante insatisfatória. $\mathrm{O}$ relevante, no entanto, é assinalar a necessidade de tal especulação, no contexto do modelo teórico de Furtado: se houve disseminação dos pagamentos na forma monetária, por um período razoável, apenas razões bem especiais poderiam impedir a formação de fluxos auto-sustentados de expansão da renda.

\section{2_Produtividade}

Furtado adota um conceito amplo de produtividade. Para ele, a produtividade na economia cresce tanto quando ocorrem inovações (novas tecnologias, reorganização do trabalho, processos produtivos mais eficientes), como quando sobe o preço do produto de exportação em relação aos custos de produção e aos preços dos produtos importados. ${ }^{7}$ Ademais, a produtividade na economia como um todo se eleva quando fatores ociosos passam a ser utilizados e/ou a receber melhor utilização. É o caso de um surto exportador agrícola apoiado em terra disponível, mão-de-obra barata (provinda do "setor de subsistência"), que requeira pouco capital; ou ainda da industrialização em presença de excedentes de mãode-obra.

De um ponto de vista esquemático, os ganhos de produtividade no período primário-exportador advêm dos dois últimos fatores: elevação do preço do produto de exportação e incorporação de fatores ociosos. O progresso técnico representaria uma característica quase exclusiva dos processos de industrialização. A visão de Furtado pode parecer esquemática, mas assim é, e a tal ponto que ele fechou os olhos à imensa maravilha tecnológica que foram os engenhos de açúcar ${ }^{8}$ e admitiu apenas pe- 
quenos avanços agronômicos no cultivo de café dos séculos XIX e XX.

Nesse contexto, é natural que as quedas de preço dos produtos de exportação e até mesmo a exaustão dos cultivos e minas sejam vistas como fatores de perda de produtividade da economia como um todo. Esses movimentos implicaram retração da renda per capita e retorno da população ocupada à "economia de subsistência", ou seja, às atividades desenvolvidas a baixos níveis de produtividade.

Até o momento de implantação de uma dinâmica industrial, a economia fica presa a este dilema: não existe um fator interno, auto-sustentado de crescimento da produtividade. ${ }^{9}$ Quedas de preços, exaustão de ciclos produtivos em razão da concorrência ou da superprodução, esgotamento de minas levam à perda de produtividade global. Simetricamente, a conexão com fontes de demanda dinâmicas do comércio internacional - açúcar, café, tabaco, metais preciosos, borracha - ocasiona um acréscimo súbito de produtividade, graças aos dois elementos mencionados: preços elevados e utilização mais intensa de fatores antes ociosos (terra, trabalho, natureza, capital).

\section{3_Preços relativos}

A ausência de considerações mais amplas sobre preços relativos representa uma das características mais notáveis dos modelos de Furtado. A rigor, Furtado preocupa-se com os preços dos produtos exportados e, no modelo de industrialização por substituição de importações, com a relação entre preços de exportação e de importação (que repercute na taxa de câmbio).

Acreditamos que a ausência de tratamento dos preços relativos não represente grande problema para o modelo de economia escravista açucareira, desde que se presuma a virtual auto-suficiência do engenho no que se refere a produtos de mercado interno. Como a totalidade das transações correspondia ao mercado internacional, o acompanhamento das relações de troca entre o produto (açúcar) e o principal insumo (os escravos) seria plenamente suficiente. ${ }^{10}$ Convém lembrar que Furtado acautela-se, atribuindo às aquisições do engenho no mercado interno um significado residual; vale dizer, inexpressivo tanto para a firma como para a economia como um todo.

Já no caso da economia mineradora, a omissão tem maiores conseqüências. Por um lado, Furtado admite que as transações monetárias são disseminadas. Por outro, do relato dos historiadores sabemos que o ciclo do ouro provocou em encarecimento de todos os gêneros e insumos, tanto os de mercado interno quanto os importados (ver Hollanda, 1960a e 1960b;

\author{
Pode-se dizer que o \\ progresso técnico na indústria \\ e nos serviços industriais \\ modernos é induzido de fora, \\ vale dizer, por inovações \\ formuladas em outros países e \\ transplantadas para os países \\ atrasados. De todo modo, \\ a dinâmica inovadora dos \\ países centrais sempre se \\ transplanta, com adaptações, \\ às economias industriais \\ retardatárias. O progresso \\ técnico não se torna \\ endógeno, mas é inevitável. \\ 10 Pode-se até mesmo admitir, \\ como Furtado faz, uma \\ contabilidade virtual da firma \\ para efeito de apuração da \\ rentabilidade do capital, \\ confrontando o preço dos \\ escravos, sua depreciação e \\ alocação nas diversas \\ atividades necessárias à \\ produção, dado o preço \\ do açúcar.
}


11 A clássica análise da industrialização substitutiva leva adianta esse tratamento, embora com sérias limitações na análise de preços relativos dos produtos de mercado interno.
Zamella, 1990). Ora, o movimento de preços relativos exerceu impacto não apenas sobre a firma mineradora, senão sobre a lucratividade dos provedores e produtores de insumos, meios de transporte, serviços. Em suma, o modelo de um único bem, ou de uma única relação de troca relevante (produto exportado versus escravos), revela-se insuficiente para a economia do ouro.

Revela-se insuficiente, do mesmo modo, para a economia do café. Admita-se que, na análise do ciclo cafeeiro, há um atenuante: Furtado lança os olhos sobre a relação de preços entre tradeables e non-tradeables, já que, ao menos no que se refere à economia cafeeira baseada no trabalho livre, os conflitos entre exportadores, consumidores e produtores vinculados ao mercado interno passam a ser levados em consideração. Vale lembrar que tais conflitos balizam a política econômica e estão presentes na análise clássica de esgotamento do ciclo cafeeiro da Formação Econômica. A rigor, são decorrências reconhecidas da política de valorização do café. Em poucas palavras, a admissão de um papel ativo para a política econômica ao longo do ciclo cafeeiro, se não representa um tratamento ampliado de preços relativos, ao menos indica alguma atenção à relação de preços entre tradeables e non-tradeables. ${ }^{11}$ No modelo de economia do ouro, a omissão no tratamento dos preços relativos é absoluta e tem conseqüências.

\section{4_Economia de subsistência}

Como vimos, a expressão "economia de subsistência" adquire significados diversos na obra de Furtado. Tanto abrange o sentido literal de produção não-excedentária quanto diversas versões atenuadas de economia de baixa produtividade. A atividade criatória do sertão nordestino, por exemplo, era considerada "de subsistência", embora provesse gado para o litoral. Mesmo após o início da industrialização, Furtado considera que boa parte da agricultura brasileira desenvolve-se em condições "de subsistência", o que, no caso, claramente designa baixa produtividade.

A noção de economia de subsistência exerce ainda papel adicional nos modelos de Furtado. Como se sabe, afora os processos produtivos baseados na mão-de-obra escrava - o escravo é caro e, por definição, um bem escasso -, os demais processos produtivos encaixam-se em variantes de um modelo de oferta ilimitada de mão-de-obra. A industrialização brasileira foi um processo com oferta ilimitada de mão-de-obra; a lavoura cafeeira assalariada, idem; as diversas atividades produtivas urbanas e rurais, do mesmo modo. Enfim, há na economia brasileira um excedente populacional que deprime os salários. Esse excedente populacional, o qual em meados do século XX deslocou-se em parte para as cidades, teve 
em épocas anteriores seu locus no meio rural e na agricultura.

A população excedente no meio rural formou-se nos tantos momentos de desagregação das atividades dinâmicas (açúcar, mineração) ou ainda pela incorporação de contingentes não suscetíveis à escravização (descendentes de indígenas, brancos pobres, escravos libertos e seus descendentes). A base da formação de bolsões de população excedente é a existência de terra livre, ou terra de ocupação acessível desde que o ocupante aceite as diversas formas de subordinação aos proprietários. Pois bem, tal população forma a base da "economia de subsistência"; vale dizer, é uma força de trabalho que pode ser atraída a baixo preço, sempre que houver oportunidades.

O curioso é que Furtado engloba nas "atividades de subsistência", nos momentos que antecedem o término da escravidão, até mesmo a população escrava. Não nos referimos, naturalmente, ao contingente escravo ocupado em culturas dinâmicas e que dedica uma parte do tempo de trabalho à produção da própria subsistência. Referimo-nos aos escravos que ficam semiociosos quando a cultura dinâmica decai, os quais, no entendimento de Furtado, não sendo transacionados, permanecem a postos para eventuais retomadas da atividade principal e/ou são alocados em atividades de baixa produtividade (nos sentidos referidos na seção 4.2). Seria o caso do litoral açucareiro nordestino, a partir do final do século XVII, e, em condições diversas, de Minas Gerais, após a exaustão das minas.

Imaginar que um cultivo pouco rentável, ou não rentável, possa manter uma população ainda escravizada, requer um pouco de imaginação, dado o valor do escravo. Pensamos, mais uma vez, que a explicação de Furtado para a "letargia secular" do Nordeste açucareiro é satisfatória. $\mathrm{O}$ entendimento de que o engenho tradicional é uma unidade econômico-social capaz de resistir às intempéries, mantendo inclusive a escravidão, parece apoiada tanto em relatos históricos quanto nos estudos que tratam da formação da estrutura social nordestina.

Imaginar que os escravos tornados ociosos pela exaustão das minas pudessem refluir às "atividades de subsistência", conservando-se o vínculo da escravidão, é mais difícil. Naturalmente, o razoável seria admitir que outras atividades rentáveis, compatíveis com o trabalho escravo, vieram a se desenvolver ou até mesmo já existiam na região. Essa admissão, no entanto, indica uma capacidade de adaptação da economia ao término de um surto exportador que colide com o núcleo explicativo de Furtado. No sistema de Furtado, o dinamismo só pode provir de surtos primário-exporta- 
dores, do aproveitamento de novas oportunidades apresentadas pelo comércio internacional de modo geral ou, finalmente, da superação da exportação de produtos primários como fator dinâmico, apenas proporcionada pela industrialização.

Ainda assim, cabe notar que a própria industrialização substitutiva é concebida tendo em vista a existência de bolsões de força de trabalho ocupada a baixos níveis de produtividade; vale dizer, dos resíduos de todos os surtos expansivos anteriores. Admitir que esses resíduos tenham em algum momento mantido a relação de escravidão requer explicações suplementares. Requer também uma análise de dinâmicas setoriais, de preços relativos, de rentabilidade, de mecanismos de formação de poupança, que penetrariam fundo na economia da escravidão no Brasil, mas em muito ultrapassariam o arcabouço dos modelos de racionalização histórica de Furtado. 


\section{Referências bibliográficas}

DEAN, W. A industrialização de São Paulo, 1880-1945. São Paulo: Difel, 1971.

FURTADO, C. A economia brasileira: contribuição à análise do seu desenvolvimento. Rio de Janeiro: A Noite, 1954.

FURTADO, C. Subdesenvolvimento e estagnação na América Latina. Rio de Janeiro: Civilização Brasileira, 1968.

FURTADO, C. Formação econômica da América Latina. Rio de Janeiro: LIA, 1969.

FURTADO, C. Formação econômica do Brasil. São Paulo: Companhia Editora Nacional, 1999.

FURTADO, C. A economia colonial no Brasil nos séculos XVT e XVII. São Paulo: Hucitec/ ABPHE, 2000.

HOLLANDA, S. B. A mineração: antecedentes luso-brasileiros. In: HOLLANDA, S. B. (Org.). História geral da civilização brasileira, tomo 1 - A Época Colonial, v. 2. São Paulo: Difel, 1960a.

HOLLANDA, S. B. Metais e pedras preciosas.

In: HOLLANDA, S. B. (Org.). História geral da civilização brasileira, tomo 1 - A Época Colonial, v. 2. São Paulo: Difel, 1960 b.
LIBBY, D. Transformação e trabalho em uma economia escravista: Minas Gerais no século XIX. São Paulo: Brasiliense, 1988.

MARTINS FILHO, A.; MARTINS, R. Slavery in a non-export economy: Nineteenth century Minas Gerais revisited. In: Hispanic American Historical Review, v. 63 , n. 3, 1983.

MARTINS, R. A economia escravista de Minas Gerais no século XIX. Belo Horizonte: Cedeplar, 1982.

PAIVA, C. A. População e economia nas Minas Gerais do século XIX. 1996. Tese (Doutorado em História) - FFLCH, Universidade de São Paulo, São Paulo, 1996.

SUZIGAN, W. Indústria brasileira: origem e desenvolvimento. São Paulo: Hucitec, 2001.

VILLELA, A. Industrial growth and industrialization: revisions in the stages of Brazil's economic development. In: VILLELA, A. A.; MARQUES, H. N. Escritos selecionados de Annibal Villela. Rio de Janeiro: IPEA, 2000.

ZEMELLA, M. P. O abastecimento da capitania das Minas Gerais no século XVTII. 2. ed. São Paulo: Hucitec/Edusp, 1990

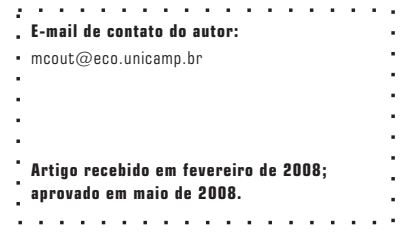

